\title{
O SIGNIFICADO DO PARTO NA VISÃO DE CASAIS GRÁVIDOS
}

\author{
Ana Márcia Spanó Nakano*
}

Marli Villela Mamede**

\begin{abstract}
RESUMO: Os programas de educação e treinamento da mulher para o parto utilizando dos métodos psicossomáticos, têm se mostrado ineficientes. O objetivo deste trabalho é identificar as idéias pré-existentes que o casal grávido atribui ao evento parto, possibilitando redirecionar os cursos de orientação pré-natal, atendendo ao casal como unidade, de modo a ajudá-lo a ter o parto que deseja. As idéias sobre o parto foram emitidas pelos casais em grupo durante o curso, utilizando-se da técnica de Brainstorming (OSBORN, 1957). O parto foi identificado como um processo biológico e inerente às mulheres, trazendo emoções variadas e ambivalentes para ambos os sexos, além de constituir-se em um momento de consolidação social dos papéis maternos e paternos. Conclui-se que o parto é um período crítico que desencadeia reações biológicas, psicológicas e sociais, sendo essencial que nos cursos se atente para o processo de significação do mesmo.
\end{abstract}

ABSTRACT: The programs of education and training for labor and delivery designed for women using psychomatic methods have been considered as inefficients. The goal of this work is to identify preconceived ideas held by the pregnant couple about labor and delivery, making it possible to redirect prenatal orientation classes and to deal with the couple as an unit, helping them to have the experience that they want. The ideas about labor and delivery were emitted by the couple during the group classes using brainstorming technique (OSBORN, 1957). Labor and delivery was identified as a biological process inherent to women, bringing up varied and ambivalent emotions for both sex besides to constitute a time of social consolidation of roles for both parents. Concluding, labor and delivery is a critical period that brings biological, psychological and social reactions, being essential that in the classes given, the meaning of it should be considered.

UNITERMOS: Parto - Psico-profilaxia - Saúde da Mulher

\section{INTRODUÇÃO}

Chertok, citado por MALDONADO(2), identifica o parto como um processo verdadeiramente psicossomático, cujas características são determinadas por fatores obstétricos, mas também por variáveis da personalidade, história pessoal e contexto social. Assim, MALDONADO(2), considera o parto como fenômeno complexo, multideterminado por inúmeras facetas do contexto social, cultural e da individualidade física e psicológica da mulher. Alerta ainda, para que os métodos de preparação para o parto sejam examinados, interpretados e reavaliados, segundo este ponto de vista.

NAKANO(3), num levantamento bibliográfico sobre o uso de programas de educação e treinamento da mulher para o parto, que utilizavam os métodos psicossomáticos propostos por Read, em 1933, Velvosky e Platnov, em 1949 e Lama-

\footnotetext{
* Professora Assistente junto ao Departamento de Enfermagem Materno-Infantil e Saúde Pública da Escola de Enfermagem de Ribeiráo Preto - USP.

** Livre-Docente junto ao Departamento de Enfermagem Materno-Infantil e Saúde Pública da Escola de Enfermagem de Ribeirăo Preto - USP.
} 
ze, em 1952, observou que as estratégias utilizadas pelos autores enfatizam a participação ativa da mulher no processo de parir, reforçando o desenvolvimento de habilidades para o controle do corpo durante o trabalho de parto. Concluiu a autora que esses programas constituem instrumento ideal para introjetar na mulher modelos ou padrões de comportamento, adequando-a ao modelo assistencial essencialmente de atenção e às variáveis biológicas.

Diante de tais considerações emerge-nos a preocupação em redirecionar os cursos de orientação pré-natal no sentido de considerar o casal grávido como unidade a ser assistida, por entender que o homem também vivencia este processo, embora não fisicamente como a mulher. Isto porque o processo de gestar, parir e amamentar repercute de forma significativa na vida do futuro pai, e sua atitude frente à situação de tornar-se pai pode ter reflexos evidentes sobre a mulher, especialmente no que diz respeito à forma como ela vivenciará o exercício da maternidade.

Consideramos ainda, que os cursos de orientação pré-natal devem adotar uma abordagem centrada no processo de significação que o casal grávido tem acerca do parto, visto que entendemos que a compreensão do significado, que os indivíduos dão aos objetos, eventos é produto da vida social. A respeito do processo de significação BLUMER(1) apresenta as seguintes premissas:

- os seres humanos agem em relação às coisas com base nos significados que as coisas têm para ele;

- o significado dessas coisas deriva, ou decorre, da interação social que um indivíduo tem com os seus semelhantes;

- esses significados são manipulados e modificados através de um processo interpretativo usado pela pessoa no trato com as coisas com que se defronta.

Frente a essa forma de entender a determinação da experiência de parto, no propusemos, através do acompanhamento de casais grávidos, a identificar as idéias pré-existentes que os mesmos atribuem ao evento parto.

\section{METODOLOGIA}

\section{Contexto do estudo}

O presente estudo exploratório foi efetuado em uma matemidade, tipo fundação, localizada na cidade de Ribeirão Preto, Estado de São Paulo. Tal instituição atende a uma clientela com convênio médico de grupo, cooperativa e ou particular.

Essa instituição vem promovendo desde 1984 cursos periódicos de preparação psico-física para o parto a casais grávidos, ministrado por enfermeiras da própria instituição.

Os grupos de casais são constituídos por indivíduos que, voluntariamente, se inscrevem no curso. A inclusão de casais independe da paridade, e é realizada a partir do $5^{\circ}$ mês de gestação.

\section{População Alvo}

Compõe-se de casais grávidos inscritos no curso de orientação pré-natal.

\section{Amostra}

Constituiu-se de 2 grupos de casais grávidos: no $1^{\circ}$ grupo participaram 9 casais e no $2^{\circ}$ grupo 7 casais com idade dos sujeitos variando entre 17 e 40 anos, sendo que apenas um destes casais já havia experenciado outras gravidezes. Todos os casais possuiam nivel superior de escolaridade.

\section{Método de Coleta d® Dados}

Quanto à estratégia para obtenção dos dados referente as idéias pré-existentes sobre parto, utilizamos a Técnica de Brainstorming (Tempestade de Idéias) idealizada por Osbom em 1957.

Brainstorming é a expressão livre das idéias pelos membros de um grupo, estimulada mutuamente(4).

Homens e mulheres foram convidados a expressarem conjuntamente e espontaneamente as idéias que vinham à mente sobre o parto, sem se preocuparem com um juizo crítico sobre a validade das mesmas. As idéias deveriam ser apresentadas de forma rápida e sucessivamente 
umas às outras.

Esclarecemos que tal técnica foi utilizada não só como estratégia para coleta de dados, mas também como aquecimento para que o grupo de casais discutisse a temática parto.

\section{Registro e Análise dos Dados}

As idéias expressas por cada sujeito foram anotadas no momento e na ordem em que as mesmas eram pronunciadas. Apesar de todo o processo de coleta de dados e discussão das idéias ter sido realizada com a dupla, tomamos o cuidado de assinalar as idéias emitidas pelas mulheres com a intenção de identificar diferenças, tendo por base a questão gênero.

A seguir, as idéias foram expostas ao grupo para serem submetidas à análise conjuntamente com eles, de forma a associar as idéias umas às outras, eliminando algumas e aprimorando outras até à chegada de consenso pelo grupo ou seja, o que significava para eles o parto.

\section{O SIGNIFICADO DO PARTO}

A análise das idéias sobre parto que apresentamos, são produto das discussões feitas com os grupos de casais grávidos, onde uma das autoras atuou como moderadora. O conteúdo das discussões foi analisado de forma que nos foi possivel identificar, no processo de significação do parto para os dois grupos de casais grávidos, categorias como: parto como processo biologico, parto como processo psico-emocional e parto como processo socio-cultural.

A relação das idéias emitidas pelos grupos de casais distribuídas nestas categorias de análise estão em anexo.

De uma forma geral, podemos observar que a categoria parto como processo biológico foi constituída de idéias inerentes às mulheres, onde se destacaram questões relacionadas à dor, anestesia, normal, Leboyer e recuperação.

Tal aspecto pode se justificar, por serem as mulheres quem efetivamente vão vivenciar fisicamente o parto. Dentre as idéias supra citadas surge a dor relacionada ao parto, cuja idéia se perpetua através dos tempos, reforçada pela Bíblia Sagrada, que aponta para uma matemidade com sacrifícios, cuja dor de parto é uma sensação que a mulher deve padecer.
No entanto, sabe-se que a sensação de dor é altamente individualizada, dependente da história e das experiências da própria pessoa, sendo ela socialmente aprendida, principalmente através da tradição cultural.

Pode-se aprender que a dor apresenta-se como uma característica inererite ao parto. A anestesia para esses casais foi considerada como parte integrante do processo de parir, ou seja, um instrumento rotineiro para alívio das dores do parto.

A idéia de normalidade expressa pela palavra normal e Leboyer nos pareceu como reflexo de uma tentativa de oposição ao excesso de intervencionismo utilizado na prática obstétrica, especialmente representado pelos altos índices de cesarianas. Convém destacar que a palavra cesariana não foi mencionada por nenhum dos participantes.

Ainda como parte desta categoria aponta-se para a preocupação com a recuperação, o retorno às condições físicas anteriores à gravidez, principalmente no que tange às questões de imagem corporal.

Tanto as mulheres e principalmente os homens, referem-se ao parto como produtor de emoções variadas e ambivalentes, como podemos observar na categoria parto como processo psicológico emocional. Os sentimentos ambivalentes no entanto foram mais expressos pelas mulheres.

A mescla de sentimentos, ora positivos ora negativos, em relação ao parto por parte das mulheres, pode ter advindo da conotação do parto enquanto um estado fisicamente sofrivel, que precisa ser enfrentado de qualquer forma, sentindo-se muitas vezes, incapaz de um controle total, além de envolver uma grande carga de responsabilidade para si, gerando emoções como: medo, incerteza, insegurança, preocupação, susto, aflição, desconhecimento.

Ao mesmo tempo, tais emoções se misturam com emoções positivas: felicidade, alegria, amor, paz, carinho, produzidas pela concretização efetiva da chegada do bebê por ocasião do parto e com ele a afirmação da identidade materna.

Para os homens, que de certa forma não vivenciam fisicamente 0 processo de parir, o significado de parto para eles remete a emoções 
quase que exclusivamente positivas: felicidade, alegria, carinho, prazer, tranqüilo, desejo, amor, vibraçăo, curtiçăo, alívio, gratificaçăo.

O parto, para o homem, constitui um momento de intensas emoções, por possibilitar a primeira aproximação direta do pai com o filho, sem intemediações pela mulher, condição necessária durante a gestação, em que o feto está incorporado ao esquema corporal da mulher.

Não só de vivências físicas e psico-emocionais se constitui o parto para estes casais, mas de uma forte carga valorativa sócio-cultural, como podemos observar na categoria parto como processo socio-cultural.

A capacidade que o casal tem de conceber, gestar e parir um filho saudável é o socialmente desejável, o que acaba por estabelecer um fortalecimento em cada um, da dupla, ou mesmo o fortalecimento da relação a dois e do papel social de bons reprodutores da espécie. Assim, os papeis matemo e patemo mostraram-se evidenciados nas falas dos homens significando a virilidade masculina: vida, saúde, realizaçåo pessoal; e na fala das mulheres significou sua capacidade para fertilidade, gestação, parturição: ter filho perfeito e saudável.

Ainda como parte desta categoria, os homens apresentaram o parto como uma situação concreta de patemidade e com isto, a aquisição de novas responsabilidades, como evidenciado nas falas: choro, dá ele para mim, tome que o filho é seu.

Outro aspecto referenciado sobre o parto, tanto pelos homens como pelas mulheres, é a simbolização do mesmo com o sexo da criança. $E$ ao fazer isso, a questão de gênero é identificada de imediato nas seguintes falas: filho, homem, menino, hi! nåo é menino. E reforçar a supremacia e a superioridade masculina, é valorizar o masculino, em detrimento do feminino, pois para eles é a garantia da manutenção do nome da família.

O cultural reflete-se nas falas masculinas, onde o parto assume o significado de um mo- mento santificado: obrigado meu Deus da qual a mulher participa em estado de graça, Virgem Maria. O corpo feminino perde por um momento a sensualidade, para dar lugar à matemidade, naturalmente imposta sobre o físico da mulher.

Podemos verificar que o parto, apesar de ser uma passagem de um estado para outro, de ocorrência abrupta e de pequena duração, frente aos demais estágios do ciclo grávido-puerperal, é um periodo crítico que desencadeia uma série de reações biológicas, sociais e psicológicas. Apreende-se que a atribuição de significados ao evento parto, está interligada a atos intelectivos (cognitivos), afetivos (sentimentos) e ativos (ação), cuja interrelação tem repercussão no modo de viver e de ser do indivíduo, ou seja, na motivação de preparar-se para o parto e na própria forma de vivenciar a situação de parto.

\section{CONSIDERAÇÕES FINAIS}

Diferentes reações que os indivíduos podem apresentar frente a este evento variam de acordo com o contexto familiar e sócio-cultural, em que a pessoa está inserida. Portanto, é essencial que a assistência ao casal grávido na preparação para o parto atente para as idéias pré-concebidas que os mesmos têm a respeito do mesmo, de modo a auxiliá-los num processo de reflexão sobre as origens destes significados, 0 que seguramente irá ajudá-los no desempenho do novo papel que se apresenta: o sermãe e pai.

Acreditamos que a possibilidade de estimular este processo de conscientização dos significados sobre o parto e a reflexão sobre suas origens permitirá ao casal grávido uma decisão mais madura da experiência do tipo de parto que desejam para si e portanto, a própria motivação de fazer, ou não, um treinamento específico para o parto. Desta forma, o assistir ao casal grávido terá por objetivo auxiliá-los a alcançar não ao parto idealizado pelo modelo biomédico vigente, mas ao parto que cada casal deseja e considera capaz de ter. 


\section{REFERÊNCIAS BIBLIOGRÁFICAS}

1. BLUMER, H. Symbolic Interactionism perspective and method. California: Prentice-hall, 1969.

2. MALDONADO, M.T. A psicologia da gravidez, parto e puerpério. Femina, v.2, n.1, p.404-410, 1974.
3. NAKANO, A.M.S. Os métodos psicossomáticos de pre paração para o parto: análise de seus objetivos $e$ finalidades. Ribeirâo Preto, 1990. 265p. Dissertaçăo (Mestrado). Escola de Enfermagem de Ribeiráo Preto da USP, 1990.

4. WARD, C.D. Psicologia Social Experimental: manual de laboratório. Traduçăo Anna Edith Bellico da Costa e Nilza Rocha Féres. Sáo Paulo: EDUSP, 1974.

Recebido para publicaçăo em 14.04.94 


\section{ANEXO - CATEGORIAS DE ANÁLISE SOBRE O SIGNIFICADO DE PARTO}

\section{Categoria Parto como Processo biológico}

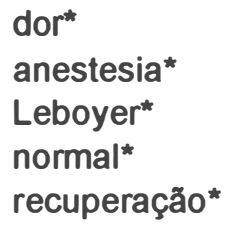

\section{Categoria Parto como Processo Psico-emocional}

\begin{tabular}{|c|c|}
\hline medo* & minha mulher tem medo \\
\hline ansiedade & incerteza* \\
\hline insegurança* & desconhecido* \\
\hline felicidade $^{\star}$ & alegria \\
\hline amor* & $\mathrm{paz}^{*}$ \\
\hline emoção & preocupação* \\
\hline susto* & carinho \\
\hline feliz ${ }^{*}$ & tranquilo \\
\hline desejo & bobeira \\
\hline alegria* & expectativa* \\
\hline vibração & amor \\
\hline curtição & aflição* \\
\hline gratificante & alivio \\
\hline
\end{tabular}

3. Categoria Parto como Processo Sócio-cultural

$\begin{array}{ll}\text { vocề }^{*} & \text { realização pessoal } \\ \text { menino* } & \text { hi! não é menino* } \\ \text { vida } & \text { virgem maria } \\ \text { saúde } & \text { perfeito, saudável } \\ \text { homem* } & \text { dá ele para mim } \\ \text { filho } & \text { obrigada meu Deus } \\ \text { choro } & \text { tome que o filho é seu }\end{array}$

OBS: as falas assinaladas por asteriscos $\left(^{\star}\right)$ são as expressas pelas mulheres. 